\title{
Research on the Construction of Hunan Regional Logistics Public Service Base
}

\author{
Shijun Yuan \\ Hunan Modern Logistics College \\ Changsha, China 410131
}

\author{
Jianhua Chen* \\ Hunan Modern Logistics College \\ Changsha, China 410131 \\ *Corresponding Author
}

\begin{abstract}
This paper starts with the analysis of the significance of the construction of Hunan regional logistics public service base. Based on the analysis of the current development status of the industry, this paper analyzes its site selection and key construction content and draws the conclusion of project construction.
\end{abstract}

Keywords-logistics; public service base; construction research

\section{INTRODUCTION}

This paper intends to promote the development of regional economy and to study the meaning of the construction of the regional logistics public service base to the standardization of modern logistics market structure, to the integration of social logistics resources, and to the development and economic benefits of Hunan logistics industry.

\section{SignificANCE OF PROJECT CONSTRUCTION}

\section{A. The Need to Promote the Sustainable Development of Regional Economy}

This project can accelerate the construction of modern logistics system in Changsha and even Hunan Province, thus effectively promoting economic cooperation and trade between enterprises, which is conducive to the comprehensive utilization and optimization of resources of various enterprises. It can also activate the market, attract investment, promote the development of the logistics industry, optimize the industrial structure, give full play to the city's potential and overall benefits, maintain the momentum of rapid economic growth, and provide favorable protection for sustainable economic development. As a result, it can promote the development of modern logistics in a broader scope and higher level.

\section{B. The Need to Integrate Social Logistics Resources to Improve the Quality of Logistics Services}

The construction of the project will significantly promote the improvement of the level of urban logistics services. At the same time, the use of the infrastructure and equipment of the public service base can provide a full range of services for social logistics companies and express delivery companies. What's more, it is also conducive to attracting more competitive external logistics enterprises to Changsha to develop their business, developing into standardized, professional and socialized logistics services, which will improve Changsha's regional logistics competitiveness and modern logistics service capabilities.

\section{The Urgent Need to Invigorate Circulation and Prosperous Trade}

The construction of this project is fully in line with the needs of Hunan's development of trade and circulation. We should comprehensively use modern technology means and management methods to achieve high-efficiency logistics operations in the field of trade and circulation and improve the quality of economic operations.

\section{THE ANALYSIS OF CURRENT INDUSTRY DEVELOPMENT ISSUES}

In recent years, the construction process of logistics parks in Changsha has been significantly accelerated, and the role of logistics parks in promoting logistics and even local economic development has become increasingly evident. However, compared with the developed regions at home and abroad, the Changsha LTL freight market needs to be upgraded and promoted. The infrastructure construction of Changsha LTL Logistics Park still lags behind the market needs, and the development level is still low. Many of the LTL logistics parks that are put into use are difficult to operate and the profit is not high. The main problems are as follows:

\section{A. LTL Logistics Enterprises Are Small, Various, and Poor}

There are about 780,000 road freight enterprises in China's inland areas, with an annual $15 \%$ growth rate. The total number of LTL enterprises exceeds that in other countries. Many of the LTL companies rely on one phone and one car to survive by price war. The top 20 roads in China's highway LTL logistics account for less than $2 \%$. In contrast, the top five LTL road transport companies in the United States monopolize $60 \%$ of the US market share. Most of China's small and medium-size logistics enterprises are obviously doing shortterm business. The messy industry environment has made many enterprises reluctant to consider the long-term development of the company, investing a small amount of funds to improve management processes and to improve the quality of logistics services. The whole industry service is homogenized, and the price becomes the main bargaining chip. 
It is a normal state of China's LTL industry to cooperate with the LTL transport and the roasted seeds and Nuts Company.

\section{B. Bottlenecks in the Development of Medium-sized Retailing Logistics Enterprises}

To develop a bigger and stronger company is the dream of every logistics enterprise's boss, but in the process of rapid development, it meets the bottleneck. Firstly, medium and small enterprises are lack of funds and difficult to raise funds. In order to develop to a higher platform, enterprises must invest a lot of money in logistics equipment, sites, branches and other aspects. However, problems such as limited capital and difficult financing guarantee restrict enterprises to develop to a higher level. Secondly, logistics talents are scarce. Logistics enterprises have long working hours, high labor intensity and cannot retain high-end talents. Managers at the grass-roots level have limited vision, which leads to the shortage of logistics management talents that can truly meet the needs of enterprises to develop to a higher level. In addition, after the family enterprise develops to a certain scale, it is restricted by various factors, such as Arima, ZJS Express and other family enterprises.

\section{The Generally Backward Level of the Highway Logistics}

In the handling, loading and unloading links of logistics, because of the low labor cost in China, our enterprises are still based on the traditional way of shouldering and carrying people, which is with low efficiency, serious damage and shortage of goods. Some substantial enterprises only supplemented by forklifts and carts. In the application of information technology, the vast majority of small cargo enterprises also use the traditional telephone, fax or mobile phone for business contact, which has little involvement in modern network technology, bar code technology, GPS technology and handheld terminal scanning technology.

\section{Potential Safety Problems}

In the cargo of small loads, $90 \%$ are heavy vehicles. They are overweight more or less, some even exceed $100 \%$ of the rated deadweight tons, and some semi-trailers even have the accident of axle being crushed. Being overweight not only reduces the life span of a car, but also tends to lead to traffic accidents, road damage and loss of life and property. Although our country is cracking down on overloading, it still cannot be forbidden.

In addition, some vehicles do not apply for the procedures for the carriage of small cargoes and replace the carriage of small cargoes with the form of ordinary cargo transport, resulting in a mixed phenomenon of fish and dragon, causing chaos in the market for the carriage of small cargoes. Some of the vehicles do not meet the conditions for carrying a load of transport. The lack of protection from the sun, rain, fire and other safety measures will result in the lack of goods in transit security guarantees. There are also some passenger buses smuggle small cargoes when the passenger flow is small, resulting in mixed passengers and cargo. It is dangerous to the safety of passengers.

\section{Project Site SELECTION AND CONSTRUCTION CONDITIONS}

\section{A. Site Overview of the Project}

The project is planned to be located in Yuhua district, Changsha city, south of Xiangfu East Road, east of WuhanGuangzhou High-Speed Railway, west of Liuyang River, on two sides of Hongqi road and north of the city expressway. It is located at the junction of urban and rural areas, close to Changsha international airport, Wuhan-Guangzhou high-speed railway, shanghai-Kunming high-speed railway, BeijingZhuhai expressway, city expressway and other traffic arteries, with obvious geographical advantages and developed transportation. The specific site selection plan shall be determined after communication and reporting with the superior competent department.

\section{B. Transportation Conditions}

With the airport expressway, Wuhan-Guangzhou highspeed railway and Shanghai-Kunming high-speed railway as the framework, the project is a new transportation hub integrating the elements of aviation, high-speed railway, subway, light rail, national highway and expressway, which is a "six-aspect integration".

Highways: Beijing-Hong Kong-Macao expressway G4, city expressway G0401, airport expressway S20 and other expressways run through the surrounding areas, and "six longitudinal and seven horizontal" urban roads interweave into a network.

Railway: Changsha south station of Wuhan-Guangzhou high-speed railway has been built in the east, Lituo station of urban subway is being built in the south, and Changsha railway station is located in the north. A comprehensive railway transportation network covering both the general railway and high-speed railway has been formed.

Aviation: airport expressway leads directly to Huanghua international airport.

\section{Geographical Conditions}

The project is planned to be located in an area with superior geographical location and unique geographical advantages. It is at the center of the new "growth pole" of Hunan economy - Changzhou-Zhuhai-Xiangtan - the demonstration zone of "two types of society". WuhanGuangzhou and Shanghai-Kunming high-speed railways meet and set up stations here, with the advantageous location of "central high-speed railway hub and southeast gateway of the provincial capital". The proposed site selection area is the core area for Hunan to promote the "integration of ChangshaZhuhai-tan" and the frontier position for Hunan to participate in the "pan-pearl river delta" regional economic cooperation.

\section{Social and Economic Conditions}

The proposed site selection area has beautiful scenery and abundant education resources. The project is surrounded by Hunan forest botanical garden, which is described as "natural oxygen bar" and covers an area of more than 3,000 acres. The 
forest coverage rate of Yuhua district is $36.03 \%$, the per capita public green space area is 18 square meters, and the excellent and good air quality rate is $92 \%$.

The logistics demand around the proposed site selection area is high, the industrial foundation is solid, and the industrial development is rapid. The industrial park, led by Changsha Yuhua District Environmental Protection Science and Technology Park, is developing rapidly. The 210 enterprises represented by BYD motor city, Zhongyan headquarters and Xiaoguang mould entered the park, attracting a total investment of more than 25 billion yuan. The enterprise cluster is accelerating its development. Yuhua district has 116 industrial enterprises above the scale and has gradually formed pillar industries such as automobile manufacturing, tobacco and food, machinery manufacturing and environmental protection technology. Regional enterprises have won 2 wellknown trademarks in China and 10 famous trademarks in Hunan province. In 2012, Yuhua district achieved a GDP of 72.767 billion yuan (including medium smoke), with an increase of $11.3 \%$ year on year. With total revenue of 9204.58 million yuan, a modern industrial new town is emerging.

The project site selection area market gathers and the commerce and trade are well-developed. "The market in Hunan relies on Changsha, and the economy of Changsha relies on Yuhua district." The area to be selected for the project has gradually formed the three business circles of Dongtang, Hongxing and Gaoqiao, as well as the three sections of cultural creativity, modern logistics and ecological leisure. Wal-Mart, Carrefour, Red Star Macaron, Pinghu Tang, BBK, Your-Mart, A Best and other world top 500 and famous large commercial groups and chain supermarkets at home and abroad gathered in the area, the cluster business circle economy is booming. The market logistics system represented by prefectural logistics, ZhongYan logistics and Gaoqiao big market logistics has gradually shaped up. The exhibition industry has gradually grown into a large scale and successfully hosted the 12th agricultural expo. Hongxing international exhibition center has undertaken more than 200 large-scale exhibitions since 2002.

\section{E. Conditions for Public Facilities}

Power supply, water supply, drainage, communication and other public facilities around the project land can meet the requirements of project construction.

The peripheral communication and cable TV systems of the project are improved, the wireless network covers the whole territory, and there is no blind area for wireless communication. The pipeline gas project covering the periphery of the project has realized ventilation.

To sum up, there are good traffic location conditions, good socio-economic environment and complete public facilities around the proposed site of the project, which are fully capable of carrying all the conditions required for the construction of the project.

\section{PROJECT CONSTRUCTION PLAN}

\section{A. The Service Area for Public Allotment of Small Carloads}

The service area for the distribution of small-weight public goods is located in the northeast of the logistics public service base. It is divided into two groups, 16 single large public distribution warehouses will be built, with each group having eight in order from north to south.

\section{B. Express Delivery Public Automatic Sorting Service Area}

The express delivery public automatic sorting service area is arranged in the south of the service area and in the small load public distribution service area, and 6 public automatic sorting warehouses are arranged from east to west.

\section{Public Transport Capacity Allocation Service Center}

The public power allocation service center is located in the southwest of the base, close to the express public automatic sorting service area, and to the north of the vehicle maintenance service area.

\section{Container Yard}

The container yard area is arranged on the west side of the public power configuration service center and on the south side of the refueling and refueling stations.

\section{E. Logistics Public Information Service Area}

The logistics public information service area is located in the west of the zero-load public distribution area, and in the north of the refueling stations and the vehicle maintenance area. From west to east, the logistics public information trading building and the logistics public information platform headquarters building are respectively arranged.

\section{F. Headquarters Base for Small and Medium-sized Logistics Enterprises}

The headquarters of small and medium-sized logistics enterprises are located in the west of the logistics public information service area, and the north of the refueling stations and the automobile maintenance area.

\section{G. Living Supporting Service Area}

The living supporting service area is arranged in the northwest corner of the logistics public service base, and the canteen, driver hotel and staff dormitory are arranged successively from west to east.

\section{CONCLUSION}

According to the requirements of resource intensification, facility modernization, hardware intelligence and management informatization, this project is to build a large-scale logistics park integrating the public distribution center of small load, the automatic distribution of express delivery, modern warehousing, multimodal transportation, public information platform of logistics, container business and exhibition and sales. 
The construction of this project will be conducive to accelerating the establishment of Hunan retail logistics and express industry cluster business circulation platform, to promote the cluster development of logistics industry, and to build a gathering area of freight and express industry. In addition, the construction of the project can solve the situation of low development level of logistics supporting industry and chaotic market order in the southern region of Changsha and create a good social environment.

Generally speaking, the project construction is very necessary and feasible.

\section{REFERENCES}

[1] Zou Xin, Ji Changlin. Prediction and analysis of construction scale of regional logistics park [J]. Railway transportation and economy. 2015(10) (in Chinese)

[2] Liao Jiangjun. Project planning of cold chain logistics and distribution trading center of agricultural products in the pearl river delta [D]. South China university of technology, 2014 (in Chinese)

[3] Huang Shizheng, Cai Xiantang. Research on Hotelling model's development strategy in China logistics park [J]. Chinese management science. 2013(S2) (in Chinese) 